Where possible the former is to be preferred as the less severe procedure. There is, however, no doubt that these hamartomas should be removed in view of the high mortality rate from haemorrhage in the reported cases. One patient in this series (case 2) was left with a hepatic lesion and only biopsy was performed. At the time of of writing she was being carefully followed up while the situation was reviewed. Her hamartoma was the least vascular in our three cases. She stopped taking oral contraceptives.

All three patients were referred to this hospital from other parts of the country for specialized liver surgery. It is not possible, therefore, to make any inferences about the incidence of hepatic hamartoma whether occurring in patients on oral contraceptives or not.

More cases will have to be described before an association between liver hamartomas and oral contraceptive therapy can be proved. It is surprising that no cases were described until recently and that none have been reported from the United Kingdom until now. In the meantime, however, it seems prudent for practitioners to exclude the presence of an epigastric mass in their patients before prescribing oral contraceptives and also to bear in mind the possibility of hepatic hamartoma or adenoma as a cause of haemoperitoneum in women on the pill.
We wish to thank Mr. Rodney Smith for his advice and for permission to report details of patients under his care, and Professor Sir Theo Crawford for his encouragement and advice on the preparation of the manuscript. We also thank Dr. J. Edmund Williams and the staff of the department of diagnostic radiology, who performed the arteriography, and Miss I. J. Underhill for the preparation of the photographs.

\section{References}

Baun, J. K., et al. (1973). Lancet, 2, 926.

Committee on Safety of Medicines (1972). Carcinogenicity Tests of Oral Contraceptives. London, H.M.S.O

Contostavlos, D. L. (1973). Lancet, 2, 1200.

Edmondson, H. A. (1958). Tumours of the Liver and Intrahepatic Bile Ducts, p. 18. Washington, D.C. Armed Forces Institute of Pathology.

Horvath, E., Kovacs, K., and Ross, R. C. (1972). Digestion, 7, 74.

Kelso, D. R. (1974), Lancet, 1, 315.

Knapp, W. A., and Ruebner, B. H. (1974). Lancet, 1, 270.

Lancet, 1973, 2, 1281 .

Symington, T. (1969). Functional Pathology of the Human Adrenal Gland, p. 157. Edinburgh, Livingstone.

Willis, R. A. (1967). Pathology of Tumours, 4th edn, p. 7. London Butterworths.

Yanoff, M., and Rawson, A. J. (1964). Archives of Pathology, 77, 159.

\title{
Comparison of Mobilization after Two and Nine Days in Uncomplicated Myocardial Infarction
}

\author{
M. J. HAYES, G. K. MORRIS, J. R. HAMPTON
}

British Medical fournal, 1974, 3, 10-13

\section{Summary}

A total of 189 patients with uncomplicated myocardial infarction were selected at random for early or late mobilization and discharge from hospital. Patients were admitted to the study after 48 hours in a coronary care unit if they were free of pain and showed no evidence of heart failure or significant dysrhythmia. Randomization was achieved by monthly cross-over of the three medical wards to which the patients were discharged. One group of patients was mobilized immediately and discharged home after a total of nine days in hospital, and the second group was mobilized on the ninth day and discharged on the 16th day. Outpatient assessment was carried out six weeks after admission. No significant differences were observed between the groups in terms of mortality or morbidity, as reflected by the incidence of recurrent chest pain or myocardial infarction, heart failure, dysrhythmia, or venous thromboembolism detected either clinically or by ${ }^{125}$ Ilabelled fibrinogen scanning.

\section{Introduction}

There is still doubt about the optimum period of bed rest and hospital stay for parients with uncomplicated myocandial infarction. Because of the risk of venous thrombosis associ-

Department of Medicine, General Hospital, Nottingham NG1 6HA M. J. HAYES, M.B., M.R.C.P., Research Fellow

G. K. MORRIS, M.B., M.R.C.P., Lecturer in Medicine

J. R. HAMPTON, D.M., M.R.C.P., Consultant Physician and Senior Lecturer in Medicine ated with immobility a short period of "bed rest seems desirable (Gibbs, 1957), and a short stay in hospital might be expected to benefit the patient psychologically (Levine and Lown, 1952). A policy of early discharge from hospital will also help to relieve pressure on beds for acutely ill patients.

As most deaths and complications from myocardial infarction occur within 48 hours of the onset of symptoms (Spracklen et al., 1968; Fulton et al., 1969) it seems reasonable that the period of hospital stay should be quite short. Several studies have compared the effect of varying periods of bed rest and hospital stay in patients with uncomplicated myocardial infarction (Harpur et al., 1971; Hutter et al., 1973; Medical Division, Royal Infirmary, Glasgow, 1973), and despite a progressive reduction in the time spent in bed and in hospital no difference between patients mobilized "early" or "late" has been observed in terms of morbidity or mortality. Here we describe a randomized trial of mobilization at 48 hours and discharge home after nine days compared with mobilization at nine days and discharge after 16 days in hospital.

\section{Patients and Methods}

Patients who had been admitted to the coronary care unit (C.C.U.) at Nottingham General Hospital because of a suspected myocardial infarction within the preceding 24 hours were considered for inclusion in the trial. All such patients had a history suggestive of myocardial infarction and the diagnosis was accepted if either characteristic E.C.G. changes or a rise in the serum enzymes (creatinine phosphokinase, aspartate aminotransferase (SGOT), lactic dehydrogenase, or hydroxybutyric dehydrogenase) were shown. All patients who survived 48 hours after admission to hospital were examined by a member of the study team. They were considered unfit for mobilization, and therefore ex- 
cluded from this study, if they had persistent chest pain, heart failure (detected either radiologically or clinically from the presence of breathlessness, basal lung crepitations, a raised jugular venous pressure, or a third heart sound), or a significant dysrhythmia. Any dysrhythmia (including a sinus tachycardia of over 110 beats/min but excluding controlled atrial fibrillation) present at 48 hours and needing treatment was considered as significant. All other patients were randomly allocated to the early or late mobilization programmes. Inevitably with such early assessment some patients were admitted to the study before the results of their cardiac enzyme estimations were available. If any were shown subsequently to have inadeauate evidence of mvocardial infarction then they were removed from the study.

The three medical firms in the hospital co-operated in the trial. All patients entering the C.C.U. remained under the care of their admitting physician and after 48 hours were transferred to that physician's ward. To avoid patients belonging to the different mobilization groups being nursed simultaneously on the same ward early or late mobilization was organized according to a ward rota. The rota, on an alternating monthly basis, assigned each ward to either early or late mobilization and this continued throughout the study year. This monthly cross-over system had several other advantages: firstly, it avoided confusion among the nursing staff; secondly, each ward was involved in both programmes, which helped to prevent any individual ward practice from influencing the results; and thirdly, it spread the seasonal variation in the incidence of myocardial infarction evenly among the three participating wards. To avoid bias in the selection of patients assessment of their fitness for entry into the trial was carried out by a member of the study team who was unaware of the ward to which the patient was due to be transferred.

Wards following the early mobilization programme ensured that the patients sat out of bed on the day that thev were transferred from the C.C.U. Thereafter no restriction was placed on the patients' activities and they were encouraged to walk around the ward and to use the ordinary ward washing and toilet facilities. The patients were discharged nine days after admission to hospital.

When a ward was following the late mobilization programme the patients were confined to bed for the first seven days after transfer from the C.C.U. though they were allowed to sit in a chair when the beds were made and also to use a commode. On the ninth day after admission to hospital they were allowed up, and from then until discharge on the 16th day they were encouraged to walk about the ward.

All patients were visited daily by a member of the study team who checked that they were adhering to the mobilization programme. The presence of any chest pain or other complaint was noted, and the patients were examined for evidence of heart failure, dysrhythmia, and venous thromboembolism. The intended programme of mobilization was discontinued in any patient, whether mobile or still confined to bed, who developed complications requiring treatment. The decision to begin treatment in any patient rested with the individual physician-in-charge.

Eighty-four (79\%) of the patients mobilized early and 62 $(76 \%)$ of those mobilized late, from whom consent had been obtained, were given an intravenous injection of $100 \mu \mathrm{Ci}$ of ${ }^{125}$ I-labelled fibrinogen. In most cases the labelled fibrinogen was given within 24 hours of admission to hospital, but in four patients it was delayed until 72 hours. Leg scanning was performed daily with a Pitman 235 localization monitor for seven days to detect the development of deep venous thrombosis (D.V.T.) in the calves. A diagnosis of venous thrombosis was made if a difference in uptake of $20 \%$ or more was shown between adjacent points on the calf or a corresponding point on the opposite limb which persisted for at least 24 hours. The physicians co-operating in this study felt that the development of a positive scan was not an indication for anticoagulation, and so no action was taken unless clinical signs of venous thrombosis or pulmonary embolus were apparent. Anticoagulants were not given as prophylaxis against reinfarction during the six-week study period.

After discharge from hospital all patients were advised to increase their activities gradually with a view to returning to work about six weeks after their infarction. No firm advice was given, however, on the actual date of return to work. They were all reviewed in the outpatient clinic by their admitting firm six weeks after their admission to hospital.

\section{Results}

During the 12 months of the study 268 patients with definite myocardial infarction survived 48 hours after admission to the C.C.U. and were therefore potentiallv available for random allocation to the early or late mobilization groups. Altogether 79 patients-31 with chest pain, 25 with dysrhythmia, 18 with heart failure, and five with other illnesses -were considered too ill for immediate mobilization at 48 hours and were therefore excluded. A total of 107 patients were transferred from the C.C.U. to a ward following the early mobilization programme, and 82 were transferred to a ward following the late programme. This discrepancy in numbers between the two groups arose because at times the wards were full and unable to accept patients from the C.C.U. When this happened the patients were transferred to the medical ward with the most empty beds, and usually this was a ward following the early mobilization programme. Owing to the heavy demand on beds during the winter the physicians in charge of one ward felt unable to allow any patients with uncomplicated myocardial infarction to remain as long as 16 days in hospital. Accordingly this ward was withdrawn from the study for two consecutive months to try and keep the numbers in the two groups as nearly equal as possible, and no patients admitted to this ward during the two-month period were included in the study.

The daily surveillance by the study team resulted in eight patients-two from the early mobilization programme and six from the late-being withdrawn from the study because of non-adherence to the protocol. In six this was because anticoagulants were inadvertantly given to young patients as prophylaxis against further myocardial infarction. Two patients refused to remain in bed for the requisite period of the late mobilization programme.

Despite the discrepancy in size between the two groups of patients they were very similar in terms of age, sex ratio, medical history, blood pressure, maximum SGOT level, and the position of infarction seen on the E.C.G. (table I). The excess of inferior infarction in both groups resulted from the larger number of patients with anterior infarction who were considered too ill to be included in the study.

The number of patients with complications requiring discontinuation of the mobilization programme is shown in

TABLE I-Comparison of Patients allocated to Early or Late Mobilization Programmes on Admission to Study. Mean Values are given \pm S.E. of Mean

\begin{tabular}{|c|c|c|}
\hline & $\underset{\text { Mobilization }}{\text { Early }}$ & $\begin{array}{c}\text { Late } \\
\text { Mobilization }\end{array}$ \\
\hline \multirow{4}{*}{$\begin{array}{l}\text { Mean age (years) } \\
\text { Sex (M:F) } \\
\text { History: } \\
\text { Mean duration of pain (hours) } \\
\text { No. with previous myocardial infarction } \\
\text { No. with previous angina } \\
\text { Mean blood pressure: } \\
\text { Systolic } \\
\text { Diastolic } \\
\text { Site of infarction (no. of patients): } \\
\text { Anterior } \\
\text { Inferior } \\
\text { Others } \\
\text { Mean SGOT (IU) }\end{array}$} & $\begin{array}{l}56 \\
93: 14\end{array}$ & ${ }_{68}^{56} \pm 140 \cdot 8$ \\
\hline & $\begin{array}{l}7 \cdot 7 \pm 1 \cdot 3 \\
25\end{array}$ & $\begin{array}{l}7 \cdot 6 \pm 1 \cdot 4 \\
16 \\
22\end{array}$ \\
\hline & $\begin{array}{r}127 \\
81 \pm 1.3\end{array}$ & $\begin{array}{r}126 \\
76 \\
\pm \\
\pm\end{array}$ \\
\hline & $\begin{array}{r}37 \\
49 \\
21 \\
146 \quad \pm 10 \cdot 1\end{array}$ & $\begin{aligned} 29 & \\
38 & \vdots \\
15 & \pm 11.9\end{aligned}$ \\
\hline
\end{tabular}


table II. The overall incidence of chest pain of any type was $17 \%$ in the early mobilization group and $25 \%$ in the late mobilization group. It was usually non-specific and insignificant. There were no statistical differences between the two groups in terms of the development of venous thromboembolism, chest pain, heart failure, or dysrhythmia. Most deaths and complications occurred within the first nine days of admission to hospital (table III). Only one patient discharged after nine days in hospital was readmitted within the next week.

TABLE II-Numbers of Patients developing Complications needing Treatment before Discharge from Hospital

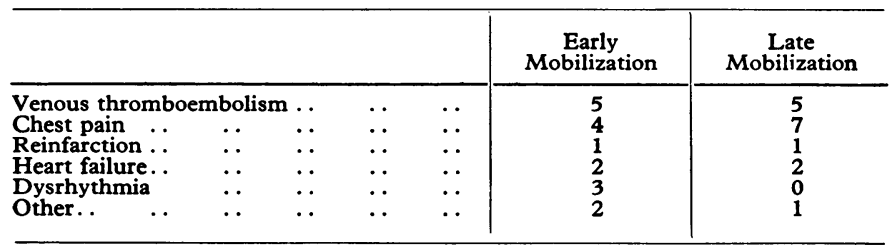

TABLE III-Daily Occurrence of Complications Within First 16 Days

\begin{tabular}{l|c|c|c|c|c|c|c|c|c|c|c|c|c|c}
\hline \multicolumn{1}{c|}{ Day } & 4 & 5 & 6 & 7 & 8 & 9 & 10 & 11 & 12 & 13 & 14 & 15 & 16 & 17 \\
\hline $\begin{array}{l}\text { Early mobilization } \\
\text { Late mobilization }\end{array}$ & 3 & 5 & 4 & 1 & 2 & 3 & & & $1 *$ & & & & & \\
\hline
\end{tabular}

Days 1 and 2 were spent in the coronary care unit. The first complications arose on day 4.

*Readmission.

Though only five patients from each group were withdrawn from the study because of venous thromboembolism some patients had signs of both deep venous thrombosis and pulmonary embolus (table IV). The frequency of isotopically diagnosed venous thrombosis was similar in the two groups.

TABLE IV-Incidence of Venous Thromboembolism during Hospital Stay

\begin{tabular}{|c|c|c|}
\hline & $\underset{\text { Mobilization }}{\text { Early }}$ & $\begin{array}{c}\text { Late } \\
\text { Mobilization }\end{array}$ \\
\hline $\begin{array}{l}\text { D.V.T: } \\
\text { Clinical } \\
\text { 12sI leg scan } \\
\text { Pulmonary embolus }\end{array}$ & $15 / 84 \underset{3}{4}(18 \%)$ & $10 / 62 \underset{2}{5}(16 \%)$ \\
\hline
\end{tabular}

The reasons for the readmission to hospital of 10 patients within six weeks of the onset of symptoms are shown in table V. Of the six patients in the early mobilization group three had been withdrawn from the study before discharge from hospital because of complications needing treatment and had been in hospital for more than the planned nine days. Of the four patients in the late mobilization group one had also been withdrawn from the study before discharge because of complications.

TABLE V-Numbers of and Reasons for Readmission within Six Weeks

\begin{tabular}{|c|c|c|c|c|}
\hline & & & $\underset{\text { Mobilization }}{\text { Early }}$ & $\begin{array}{c}\text { Late } \\
\text { Mobilization }\end{array}$ \\
\hline $\begin{array}{lll}\text { Chest pain } & \ldots & \ldots \\
\text { Reinfarction } & & \\
\text { Left ventricular } & \text { failure } \\
\text { Others } & . & \ldots\end{array}$ & $\begin{array}{l}\cdots \\
\cdots \\
\cdots\end{array}$ & $\begin{array}{l}\ldots \\
\cdots \\
\cdots\end{array}$ & $\begin{array}{l}2 \\
1 \\
2 \\
1\end{array}$ & $\begin{array}{l}2 \\
1 \\
1 \\
0\end{array}$ \\
\hline . & & Total & 6 & 4 \\
\hline
\end{tabular}

The mortality rate at six weeks in the patients mobilized early was $6.7 \%$ (7 patients) while that in the patients mobilized late was $7.3 \%$ (6 patients). Four of the patients who had been mobilized early died in hospital, and the other three died at home before their follow-up appointment. None in the late group died after discharge from hospital. This difference was not statistically significant, however, and moreover, two of the three patients who died at home had been kept in hospital for more than the intended nine days.

Six weeks after admission $83(79 \%)$ of the patients mobilized early and $56(74 \%)$ of those mobilized late who had not developed any significant complications and who had not needed readmission were due to be seen in the outpatient clinic. A small number in each group did not attend, but inquiry showed them to be alive at the sixth week. Of those attending there were no significant differences between the two groups of patients in the prevalence of chest pain, heart failure, or in the amount of activity undertaken (table VI). Only about $2 \%$ of each group had returned to work.

TABLE VI-Outpatient Assessment at Six Weeks. Mean Values are given \pm S.E. of Mean

\begin{tabular}{|c|c|c|}
\hline & $\underset{\text { Mobilization }}{\text { Early }}$ & $\begin{array}{c}\text { Late } \\
\text { Mobilization }\end{array}$ \\
\hline $\begin{array}{l}\text { No. attending clinic } \\
\text { No. alive but not seen } \\
\text { No. with angina } \\
\text { Mean heart rate/min } \\
\text { Mean blood pressure: } \\
\text { Systolic } \\
\text { Diastolic } \\
\text { No. with heart failure } \\
\text { Mobility: } \\
\text { No. At work } \\
\text { No. walking out of house } \\
\text { No. confined to house }\end{array}$ & $\begin{array}{r}78 \\
5 \\
15 \\
82 \pm 1 \cdot 7 \\
143 \pm 3 \cdot 0 \\
85 \pm 1 \cdot 6 \\
1 \\
2 \\
71 \\
5\end{array}$ & $\begin{array}{r}53 \\
3 \\
7 \\
84 \pm 1 \cdot 6 \\
142 \pm 3 \cdot 3 \\
84 \pm 1 \cdot 7 \\
1 \\
2 \\
48 \\
3\end{array}$ \\
\hline
\end{tabular}

\section{Discussion}

All previous trials making a comparison between early and late mobilization after uncomplicated myocardial infarction have shown no differences in terms of mortality or morbidity, (Harpur et al., 1971; Hutter et al., 1973; Medical Division, Royal Infirmary, Glasgow, 1973). Overall mortality in the different series has depended to a large extent on the day of selection for random allocation into early and late groups and also on the length of time elapsing from the date of infarction to follow-up assessment. In early studies by Groden et al. (1967) and Takkunen et al. (1970) the patients were not graded as "complicated" and "uncomplicated," nor were their mobilization groups randomized, so comparison with these studies is impossible. Harpur et al. (1971) initially divided their patients into complicated and uncomplicated groups at 48 hours, but as their earliest mobilization date was eight days after admission to hospital they excluded from their final assessment all patients who died or developed complications within the first seven days. Hutter et al. (1973) and the Medical Division, Royal Infirmary, Glasgow (1973) assessed their patients for admission to their studies at six and seven days respectively. Similarly, the period of time elapsing to follow up has varied, but the findings of Harpur et al. (1971) and the Glasgow study Medical Division, Royal Infirmary, Glasgow, (1973) can be directly compared with our trial as they initially evaluated their patients at about six weeks after hospital admission. In terms of the overall mortality, and bearing in mind the dates of selection for the respective studies, our figures of $6.7 \%$ in the early mobilization group and $7.3 \%$ in the late mobilization group are very similar to the results of both these trials. Harpur et al. (1971) found that $38 \%$ of all the deaths occurred in the second week, but we did not find a significant number during this period. It would, therefore, 
seem that clinical assessment of myocardial infarction patients at 48 hours is a reliable means of selecting the uncomplicated cases and that immediate mobilization of these patients is not associated with any increase in mortality.

Similar problems arise when comparing morbidity figures from the different trials. Our study was mainly concerned with the short-term problems that were most likely to relate to the duration of bed rest. As might be expected the incidence of complications fell with increasing time from the onset of the myocardial infarction. From the end of the second week to six weeks after the date of infarction our total morbidity, including death, readmission to hospital, or the development of complications restricting activities, was $5.7 \%$ in the early mobilization group and $6.6 \%$ in the late mobilization group. Harpur et al. (1971) found $7 \cdot 7 \%$ in the early and $7.4 \%$ in the late group developed such complications over a similar period.

We were particularly interested to know whether the period of bed rest affected the development of deep venous thrombosis. A positive ${ }^{125}$ I-labelled fibrinogen calf scan occurred in $18 \%$ of the patients mobilized early and in $16 \%$ of those mobilized late. This incidence is similar to the findings of Warlow et al. (1973) but considerably lower than that of earlier authors (Maurer et al., 1971; Simmons et al., 1973). A more detailed report of these figures is being prepared, but it does seem that bed rest of the duration used in this study does not affect the incidence of deep venous thrombosis detected either clinically or by ${ }^{125}$ I-labelled fibrinogen scanning. The incidence of both clinical deep venous thrombosis and pulmonary embolus was low in both groups and did not contribute to the mortality in either group.

The short duration of hospital stay in both groups was not associated with a significant increase in readmissions. Of the 10 patients readmitted, four had already been removed from the study because of complications within the first nine days of their admission to hospital.

After discharge from hospital all patients were told to increase their activities progressively. At the outpatient visit six weeks after their hospital admission we did not detect any lack of willingness on the part of the patients, their relatives, or their family doctors to follow this advice. Over $90 \%$ of the patients were ready to return to work but before doing so were awaiting instructions from the hospital physicians.

A policy of early discharge from hospital is probably beneficial to the patient from a psychological point of view (Levine and Lown, 1952). It is undoubtedly of value to a busy general hospital which is short of beds for acutely ill medical patients. It seems that most patients who seem well at 48 hours after the onset of the symptoms of a myocardial infarction need no further treatment and possibly could be discharged from hospital. Nevertheless, $18 \%$ of our patients either died or developed a complication needing treatment during the first nine days of their illness, even though they had been apparently well after the first 48 hours. Therefore, unless it is possible to identify the patients who will develop complications it seems that the period of hospital stay cannot be shortened much further. Various methods of selecting the high risk patients have been described (Norris et al., 1969; Wilson and Pantridge, 1973), and we are continuing to study this problem.

We thank Professor J. R. A. Mitchell, Dr. S. Allison. Dr. M. Knapp, Dr. P. J. Toghill, and Dr. M. V. Wells for their help. We are also grateful for the co-operation of the junior hospital staff and the nursing staff of the coronary care unit and the medical wards of Nottingham General Hospital and for the skilled technical help of Mrs. E. Holland. The contents of this paper were presented to the British Cardiac Society in December 1973.

\section{References}

Fulton, M., Julian, D. G., and Oliver, M. F. (1969). Circulation, Supplements, 39-40, No. IV, p. 182.

Gibbs, N. M. (1957). British fournal of Surgery, 45, 209

Groden, B. M., Allison, A., and Shaw, G. B. (1967). Scottish Medical fournal, $12,435$.

Harpur, J. E., et al. (1971). Lancet, 2, 1331.

Hutter, A. M., et al. (1973). New England fournal of Medicine, 288, 1141. evine, S. A., and Lown, B. (1952). Journal of the American Medical Associa tion, 148, 1365 .

Maurer, B. J., Wray, R., and Shillingford, J. P. (1971). Lancet, 2, 1385.

Medical Division, Royal Infirmary, Glasgow. (1973). Lancet, 2, 346.

Norris, R. M., et al. (1969). Lancet, 1, 274.

Simmons, A. V., Sheppard, M. A., and Cox, A. F. (1973). British Heart fournal, 35, 623 .

Spracklen, F. H. N., et al. (1968). British Medical fournal, 4, 364

Takkunen, J., et al. (1970). Acta Medica Scandinavica, 188, 103.

Warlow, C., et al. (1973). Lancet, $2,934$.

Wilson, C., and Pantridge, J. F. (1973). Lancet, 2, 1284.

\title{
Ward Design in Relation to Postoperative Wound Infection: Part III
}

\author{
G. SMITH， J. R. C. LOGIE， A. MACDONALD， H. G. SMYLIE
}

British Medical fournal, 1974, 3, 13-15

\section{Summary}

The wound infection rates, nasal carriage rates, and nasal colonization rates were studied in a recently built surgical unit for two years when it was first opened. Five years later a further two-year period of study was undertaken.

Judging by the incidence of postoperative wound infection, as far as both Staphylococcus pyogenes and Gram-negative

University of Aberdeen, Aberdeen AB9 2ZD

G. SMITH, CH.M., F.R.C.s., Regius Professor of Surgery

J. R. C. LOGIE, M.B., CH.B., Lecturer in Surgery

A. MACDONALD, M.A., M.D., Professor of Bacteriology

H. G. SMYLIE, M.D., M.R.C.PATH., Senior Lecturer in Bacteriology organisms are concerned, there is no evidence that the environment has become less safe with use over the seven-year period since opening.

\section{Introducton}

In 1971 we published the results of a study of the effect of ward design on postoperative wound infection (Smylie et al., 1971; Davidson et al., 1971 a). This study was based on the epidemiology of wound infection during the period October 1964 to September 1966, when the professorial surgical unit occupied two "Nightingale"-type wards, and during a similar two-year period from October 1966 to September 1968, when a new "race track" ward of similar size was used.

While the improvement in postoperative wound infection rates was striking it was necessary to bear in mind that the 